\title{
O Ensino Remoto Emergencial e o Ensino da Matemática: Percepção dos Estudantes e Professores de Matemática Durante a Pandemia do Novo Coronavírus na Cidade de Desterro-PB
}

Emergency Remote Education and Mathematics Teaching: Perception of Mathematics Students and Teachers During the New Coronavirus Pandemic in the City of Desterro-PB

Flávia de Souza Lima Gonçalves ${ }^{1 *}$ Douglas da Silva Cunha1

1 Instituto Federal da Paraíba, BR 110, s/n - Alto da Tubida, Patos - PB, Brasil

*flavialima0605@gmail.com

\section{Resumo}

Com a crise sanitária causada pela COVID-19, diversas áreas no mundo foram modificadas. No cenário educacional não foi diferente; entre essas modificações, a necessidade do fechamento das instituições escolares de forma repentina, passando a exigir um novo modelo educacional, a partir de uma maior utilização das tecnologias e o cumprimento de medidas para a prevenção à disseminação do vírus. Nesse cenário, este estudo tem, em sua gênese, a percepção dos estudantes e professores sobre o ensino da Matemática durante a pandemia do novo coronavírus. Foi baseado em uma abordagem quali-quantitativa, cujo método adotado foi o estudo de caso, a partir da análise de um questionário on-line respondido por 03 (três) professores de Matemática e 69 (sessenta e nove) estudantes, ambos do Ensino Médio da cidade de Desterro-PB, cujo objetivo principal foi apresentar a percepção dos professores de Matemática e dos estudantes do Ensino Médio da referida cidade sobre as aulas remotas de Matemática durante a pandemia. O trabalho teve como fundamentação teórica os estudos dos autores Costa (2020), Cordeiro (2020), Vercelli (2020), Garcia (2020), Motin (2020) entre outros. Os resultados da pesquisa apontam que o ensino remoto emergencial é um desafio para o ensino e aprendizagem, pois este surgiu de maneira inesperada para todos os envolvidos e, embora muitos estudos passassem a abordar esse tema, ainda estamos Ihe dando com algo novo, que carece ser revisto e moldado para se tornar acessível a todos.

Palavras-chave: Ensino remoto. Ensino da matemática. Tecnologias. Pandemia.

\section{(c) (i)}

Recebido 20/05/2021 Aceito 16/08/2021 Publicado 24/08/2021

\section{COMO CITAR ESTE ARTIGO}

ABNT: GONÇALVES, F. S. L.; CUNHA, D. S. O Ensino Remoto Emergencial e o Ensino da Matemática: Percepção dos Estudantes e Professores de Matemática Durante a Pandemia do Novo Coronavírus na Cidade de Desterro-PB. EaD em Foco, v. 11, n. 1, e1505, 2021. DOI: https://doi.org/10.18264/eadf.v1111.1505 


\section{Emergency Remote Education and Mathematics Teaching: Perception of Mathematics Students and Teachers During the New Coronavirus Pandemic in the City of Desterro-PB}

\section{Abstract}

With the health crisis caused by COVID-19, several areas in the world have been modified. In the educational scenario, among these changes, the need for the sudden closure of school institutions was not different, starting to demand a new educational model, based on greater use of technologies and compliance with measures to prevent the spread of the virus. In this scenario, this study has in its genesis, the perception of students and teachers about the teaching of Mathematics during the pandemic of the New Coronavirus. It was based on a quali-quantitative approach, whose method adopted was the case study, from the analysis of an online questionnaire answered by 03 (three) Mathematics teachers and 69 (sixty-nine) students, both from High School from the city of Desterro-PB, whose main objective was to present the perception of mathematics teachers and high school students in that city about remote mathematics classes during the pandemic. The work had as theoretical basis the studies of the authors Costa (2020), Cordeiro (2020), Vercelli (2020), Garcia (2020), Motin (2020) among others. The results of the research point out that emergency remote education is a challenge for teaching and learning, as it emerged in an unexpected way for everyone involved and, although many studies have started to address this topic, we are still giving you something new, which needs to be addressed. be revised and shaped to make it accessible to everyone.

Keywords: Remote education. Mathematics teaching. Technologies. Pandemic.

\section{Introdução}

No início do ano 2020, a Organização Mundial da Saúde (OMS) alertou toda a população sobre uma pandemia por novo coronavírus, o vírus SARS-CoV-2 causador da COVID-19. Devido às suas características patogênicas e epidemiológicas, o uso de álcool em gel 70\% e máscaras foram indicados para a prevenção de contaminação pelo vírus. Assim sendo, várias medidas de prevenção foram tomadas para tentar conter a propagação da COVID-19, entre elas, o fechamento de fronteiras, isolamento social, os comércios funcionando apenas os serviços essenciais e "substituição das aulas presenciais por aulas em meios digitais enquanto durar a situação de pandemia do novo coronavírus"(Portaria MEC N³43, 2020).

Mesmo diante desse cenário pandêmico, a educação necessitou prosseguir, havendo a necessidade de repensar o ensino-aprendizagem, e assim, um novo método de ensino teve que ser implantado, o ensino remoto emergencial. Estudantes e professores tiveram que, de forma urgente, se adequar às atuais circunstâncias pandêmicas, surgindo as dificuldades, pois maior parte desse ensino é baseado no uso de tecnologias.

Segundo Behar (2020);

"O termo "remoto" significa distante no espaço e se refere a um distanciamento geográfico. O ensino é considerado remoto porque os professores e alunos estão impedidos por decreto de frequentarem instituições 
educacionais para evitar a disseminação do vírus. É emergencial porque do dia para noite o planejamento pedagógico para o ano letivo de 2020 teve que ser engavetado".

Ainda que este formato de ensino esteja direcionado para o uso de tecnologias digitais, o ensino remoto não é o mesmo que ensinar a distância (EaD), pois esta tem sua própria concepção teórico-metodológica e se desenvolve em um ambiente de aprendizagem virtual, com material pedagógico específico e apoio de tutores.

Contudo, é necessário destacar que os desafios de ensinar remotamente são inúmeros, entre esses, podemos frisar que as ferramentas tecnológicas precisam ter parâmetros de qualidade e a desigualdade de acesso às tecnologias, pois nem todos os estudantes possuem a ferramenta adequada ou até mesmo o acesso à internet. Mas com tudo isso, a melhor solução para esse momento de pandemia que estamos vivenciando foi o ensino remoto, pois este tem como fundamento não atrasar o ensino e aprendizagem.

Neste sentido, motiva a pesquisa a resposta ao seguinte questionamento: Qual o nível de satisfação e qualidade do ensino remoto durante as aulas de Matemática no Ensino Médio da cidade de Desterro - PB?

Nessa circunstância, este trabalho constitui-se de um estudo de caso com abordagem quali-quantitativa, cujo objetivo central é apresentar a percepção dos professores e estudantes do Ensino Médio da cidade de Desterro-PB, sobre o ensino remoto de Matemática durante a pandemia do novo coronavírus. E como específicos: apresentar algumas dificuldades que podem ser encontradas pelos professores de Matemática no uso de tecnologias nas aulas; avaliar o nível de aprendizagem dos estudantes do Ensino Médio nas aulas remotas de Matemática e considerar o nível de satisfação dos estudantes sobre o ensino remoto.

Para tanto, utilizou-se como referências principais Costa (2020), Cordeiro (2020), Vercelli (2020), Garcia (2020), Motin (2020) entre outras. Nesse sentido, para melhor compreensão do nosso trabalho, além dessa introdução, o referencial teórico está dividido em três momentos: o primeiro faz considerações sobre a pandemia e ensino remoto emergencial; no segundo, aborda a educação Matemática e as tecnologias, e o terceiro trata de algumas considerações sobre a formação continuada de professores. Em seguida, trazemos a metodologia escolhida para o percurso do nosso estudo, logo após, apresentamos as análises interpretativas e, por fim, trazemos nossas considerações sobre os achados e apontamos a necessidade da continuidade da discussão por meio de pesquisas futuras.

\section{Referencial teórico}

\subsection{A pandemia e o ensino remoto emergencial}

O mundo vem sofrendo bruscamente em função da pandemia do novo coronavírus, este tem instigado uma maneira inesperada de convívio social, impossibilitou reuniões, atividades familiares, de trabalho, de lazer, de estudo, entre outros, e por consequência, as relações que se estabeleciam dentro das salas de aula.

As instituições escolares tiveram por recomendação da saúde, fechar suas portas e dar continuidade às atividades por meio do ensino remoto emergencial. Nele, as aulas são ministradas de maneira on-line, em tempo real ou gravadas, são as chamadas síncronas ou assíncronas. De acordo com Vercelli (2020) essa foi uma alternativa para que as atividades não ficassem paralisadas e os estudantes não serem afetados em seu processo de aprendizagem.

Morais et al explanam que embora esteja diretamente ligado ao uso da tecnologia digital, o ensino remoto não é sinônimo de Educação a Distância (EaD), sendo esta considerada uma modalidade que possui uma concepção teórico-metodológica própria e se desenvolve em ambiente virtual de aprendizagem, 
com materiais e suporte de tutores, sendo na maioria das vezes, assíncrona, isto é, sem uma predeterminada hora, auto instrucional.

\begin{abstract}
A Educação a Distância é a modalidade educacional na qual a mediação didático-pedagógica nos processos de ensino e aprendizagem ocorre com a utilização de meios e tecnologias de informação e comunicação, com estudantes e professores desenvolvendo atividades educativas em lugares ou tempos diversos. Esta definição está presente no Decreto 5.622, de 19.12.2005 (que revoga o Decreto 2.494/98), que regulamenta o Art. 80 da Lei 9.394/96 (LDB).
\end{abstract}

O ensino remoto possibilita a utilização de plataformas educacionais como $S / G A A^{1}$ e $M O O D L E^{2}$, aplicativos como Hangouts/google meet ${ }^{3}$, Zoom ${ }^{4}$ ou redes sociais, bem como a introdução de instrumentos auxiliares e a admissão de práticas inovadoras. A variedade de métodos e estratégias, bem como de práticas, é definida a partir da proximidade e competência do professor em adotar tais recursos.

A proposta é que professor e estudantes de uma turma tenham interações nos mesmos horários em que as aulas da disciplina ocorriam no modelo presencial. Com esta dinâmica é possível ser mantida a rotina de sala de aula em um ambiente virtual acessado por cada um, em diferentes localidades. Para as aulas remotas, se faz necessário o uso de plataformas digitais para esse encontro por "telas". (MOTIN et al, 2020, p. 2).

Mesmo diante deste cenário de pandemia, a grande maioria não estava preparada para utilizar o ensino remoto. Houve-se a necessidade de se reinventar e repensar o processo de ensino-aprendizagem, obrigando professores e estudantes a se enquadrarem às novas exigências estabelecidas, sem o devido planejamento e formação docente.

O ensino remoto, assim como as aulas presenciais, independente do ambiente, é um desafio para o professor, pois são sempre surpreendidos por situações inesperadas e desafiadas a propor soluções e os componentes curriculares, os conteúdos, a avaliação e a interação entre as pessoas estarão sempre presentes. E tudo isso mostrou a sociedade que as instituições escolares e seus profissionais devem estar preparados para enfrentarem acontecimentos inesperados como a pandemia enfrentada atualmente.

Assim sendo, esta pandemia da COVID-19, trouxe novos desafios não apenas para a área de Matemática, mas para o mundo, pois tiveram que se abster-se de ocasiões presenciais. O ensino remoto foi tido como uma alternativa encontrada para a demanda emergencial e com certeza, muitas experiências serão aproveitadas quando ocorrer o retorno ao ensino presencial.

\title{
2.2 A educação matemática e as tecnologias
}

Diante das transformações que a sociedade passou e vem passando nos últimos anos, a educação matemática foi umas das que mais se afligiu com essas mudanças e a adaptação das instituições escolares

\footnotetext{
1 Sistema Integrado de Gestão de Atividades Acadêmicas (SIGAA) é o espaço para gerenciamento de disciplinas e de todas as informações relativas à vida acadêmica do aluno.

2 Moodle (Modular Object-Oriented Dynamic Learning Environment) é um software livre e gratuito de gerenciamento para criação de cursos online, uma plataforma de apoio à aprendizagem/ ensino a distância.

3 Google Meet (anteriormente chamado de Hangouts) é a ferramenta de videoconferências do Google.

4 Zoom é uma uma ferramenta para realização de web conferências que pode ser utilizado para gravar a tela do seu compu-
} tador, gravar tutoriais e videoaulas. 
ao uso das Tecnologias da Informação e Comunicação (TICS), pois estas ainda são um desafio para alguns professores, pois não possuem domínio dos instrumentos tecnológicos. De acordo com Santos e Souza (2010, p. 10), “[...] faz-se necessário, incluir digitalmente os professores com estudo na formação acadêmica e na formação continuada [...]", ou seja, é de extrema necessidade que o professor esteja sempre em formação, pois o avanço da tecnologia vem ocorrendo constantemente.

Fazer uso dessas ferramentas tecnológicas no processo de educação Matemática pode favorecer o processo ensino-aprendizagem, pois possibilita uma interação maior dos estudantes com os assuntos estudados, já que estes se sentem mais atraídos pela era digital. Para firmar isso, "o uso de mídias tecnológicas existentes e em condições de produzi-las e/ou usá-las, enquanto mídia educativa, torna o ato de estudar mais agradável e interessante" (SANTOS e SOUZA 2010, P. 13). Assim sendo, esses instrumentos podem ajudar a suavizar a Matemática, que muitas vezes é tida como a vilã da escola. Aplicativos e plataformas podem favorecer essa união da Matemática e a tecnologia, entre eles, podemos citar o GeoGebra, o Kahoot, Poly Pro e Euclidea.

Aprender por intermédio de tecnologias tem diversas vantagens, entre elas: tornam a informação e o conhecimento mais acessíveis, e os alunos podem acessar recursos de informação mais ricos por meio dos recursos tecnológicos; a aprendizagem pode ser ampliada e, desde que os estudantes possam acessar a tecnologia, eles podem aprender qualquer coisa, a qualquer hora, em qualquer lugar; as tecnologias permitem que os estudantes personalizem o aprendizado. Nesse sentido, Moran contribui:

\begin{abstract}
As tecnologias são pontes que abrem a sala de aula para o mundo, que representam, medeiam o nosso conhecimento do mundo. São diferentes formas de representação da realidade, de forma mais abstrata ou concreta, mais estática ou dinâmica, mais linear ou paralela, mas todas elas, combinadas, integradas, possibilitam uma melhor apreensão da realidade e o desenvolvimento de todas as potencialidades do educando, dos diferentes tipos de inteligência, habilidades e atitudes (MORAN, 2007, p. 164).
\end{abstract}

Complementando, Levy apud Cordeiro destaca que

\begin{abstract}
Não se trata aqui de utilizar as tecnologias a qualquer custo, mas sim de acompanhar consciente e deliberadamente uma mudança de civilização que questiona profundamente as formas institucionais, as mentalidades e a cultura dos sistemas educacionais tradicionais e, sobretudo, os papéis de professor e de aluno (LEVY apud CORDEIRO, 2020, p.06).
\end{abstract}

Portanto, as tecnologias vêm para nos proporcionar uma educação de qualidade, com inclusão digital e dinamismo, no processo de ensino-aprendizagem. No entanto, as vantagens são inúmeras quando se trata de utilizá-las de forma organizada e adequada, pois se percebe a sua importância como ferramenta pedagógica em nossa sociedade.

Não há dúvida quanto à importância do professor no processo educativo. Fala-se e propõe-se tanto educação a distância quanto outras utilizações de tecnologia na educação, mas nada substituirá o professor. Todos esses serão meios auxiliares para o professor. Mas o professor, incapaz de se utilizar desses meios, não terá espaço na educação. O professor que insistir no seu papel de fonte e transmissor de conhecimento está fadado a ser dispensado pelos alunos, pela escola e pela sociedade em geral. O novo papel do professor será o de gerenciar, de 
facilitar o processo de aprendizagem e, naturalmente, de interagir com o aluno na produção e crítica de novos conhecimentos (D'AMBROSIO 1996, p. 79-80).

Assim sendo, o uso das TICs na educação em geral é de suma importância, mas jamais substituíra o professor; são apenas ferramentas de auxílio para mediar os conteúdos a serem abordados, o seu uso é exigido cada vez mais pela sociedade. Como D’Ambrósio enfatiza, o professor que insistir em não utilizá -las, não terá espaço na educação.

Diante disso, Frizon et al ressalta que não há como esquivar-se das mudanças na tecnologia e nas necessidades decorrentes dessas mudanças. Resistência, medo de coisas novas e de arriscar, à primeira vista, são obstáculos - e não cabem mais, está na hora de inovar, buscar novas alternativas, melhorar, entender e usar tudo o que as tecnologias têm a nos ofertar.

\subsection{A formação continuada de professores: algumas considerações}

Vivemos atualmente numa época de diversas transformações, tornando-a mais ampla e complexa em termos de relações sociais, de trabalho, da forma como os sujeitos vivem e atuam no mundo. Essas modificações implicam que as instituições escolares necessitam estar sempre se atualizando, para que faça sentido. Assim sendo, os docentes precisam constantemente ficar atualizados, repensando o fazer pedagógico, "de modo que atendam às necessidades educacionais e as demandas trazidas pelos alunos para o contexto escolar" (FRIZON et al, 2015, p.04).

Neste sentido o professor, precisa estar sempre se inovando e se atualizando, para acompanhar as mudanças na educação nos dias de hoje, onde a informação deixou de ser privilégio da escola, as aulas tradicionais já não estão mais suprindo a aprendizagem dos estudantes. “Provocar nas novas gerações o desejo e a curiosidade para aprender passa pela real necessidade de inovar o ensino-aprendizagem, procurando novas soluções para a construção do saber" (SILVA et al, 2012).

Sabe-se que a formação inicial do professor é de suma importância, mas ela por si só, não consegue atender a atual demanda educacional que proporciona constantes mudanças. Nesta perspectiva, a formação continuada de professores permitirá ao docente dar continuidade a obtenção de conhecimentos peculiares de sua profissão.

O termo formação continuada é toda aquela que ocorre depois da formação inicial/base. Conforme Chimentão (2009, p.03), formação continuada é "um processo permanente de aperfeiçoamento dos saberes necessários à atividade profissional, realizado após a formação inicial, com o objetivo de assegurar um ensino de melhor qualidade aos educandos".

Segundo Candau apud Chimentão (2009, p.04), três aspectos são fundamentais para o processo de formação continuada de professores:

[...]primeiro, partir das necessidades reais do cotidiano escolar do professor; depois, valorizar o saber docente, ou seja, o saber curricular e/ ou disciplinar, mais o saber da experiência; por fim, valorizar e resgatar o saber docente construído na prática pedagógica (teoria + prática).

Assim sendo, a formação continuada passa a ser um dos pré-requisitos básicos para a transformação docente e de sua prática na sociedade atual, contribuindo, portanto, para a construção dos saberes docentes que tem como base a formação inicial e consolida-se na formação continuada. 
Compreende-se, portanto, que a formação do professor é um processo imenso e complexo, contornando diversos conhecimentos, capacidades e entendimentos que irão permitir uma base para o profissional que se compromete a desempenhar a profissão da docência e realize a sua função de formar seres humanos críticos e ativos na sociedade.

\section{Metodologia}

A abordagem adotada neste estudo possui um caráter quali-quantitativo, que de acordo com Prodanov (2013, p. 70), "pesquisa tem o ambiente como fonte direta dos dados. O pesquisador mantém contato direto com o ambiente e o objeto de estudo em questão, necessitando de um trabalho mais intensivo de campo". Prodanov (2013, p. 69) enfatiza que a pesquisa quantitativa,

considera que tudo pode ser quantificável, o que significa traduzir em números opiniões e informações para classificá-las e analisá-las. Requer o uso de recursos e de técnicas estatísticas (percentagem, média, moda, mediana, desvio-padrão, coeficiente de correlação, análise de regressão etc.).

A natureza da pesquisa é descritiva e exploratória, recorrendo à técnica de análise do Estudo de Caso, pois permite com que o pesquisador analise um determinado campo dentre as demais, aprofundando seu conhecimento sobre um determinado assunto.

A coleta de dados ocorreu mediante a aplicação de dois formulários, por meio do aplicativo WhatsApp e a plataforma Google Forms em janeiro de 2021. Os questionários são semi estruturados, sendo um para os professores composto por cinco questões objetivas e outro para os alunos compostos por sete questões também objetivas com objetivo principal de apresentar a percepção dos professores de Matemática e dos estudantes do Ensino Médio da referida cidade sobre as aulas remotas de Matemática durante a pandemia. Com o desenvolver do trabalho, inquietou-se a necessidade de verificar a formação docente dos professores investigados, e essa coleta de dados foi realizada através do aplicativo WhatssApp.

\section{Resultados e discussão}

\subsection{Professores e o ensino remoto}

A partir da análise de dados coletados por meio do questionário aplicado aos professores de Matemática do Ensino Médio da cidade de Desterro - PB, pode-se observar que todos os professores investigados já faziam uso tecnologias em suas aulas de Matemática. E isso é relevante, pois de acordo com Oliveira e Moura (2015, p.78/79) “As TIC quando são utilizadas, melhoraram o processo de ensino, pois criam ambientes virtuais de aprendizagem, colaborando com o aluno na assimilação dos conteúdos". Para resguardar a identidade dos professores investigados, estes foram classificados como P1, P2 e P3.

Indagou-se qual a formação dos professores de Matemática investigados e todos possuem pós-graduação, isso significa dizer que estes deram continuidade a sua formação inicial e estão sempre se atualizando para um bom desempenho educacional.

Com o intuito de verificar o nível de aprendizagem dos estudantes na visão dos professores, colocouse em questão no segundo item do formulário, em escala variando de 1 a 5 , sendo 5 a mais alta, como eles avaliaram essa aprendizagem e pode-se constatar que cada um dos pesquisados deu uma opinião diferenciada, o P1 disse assinalou número 2, P2 o número 3 e P3 o número 4. Segundo Lima apud Moura 
(2019 p.3) “a facilidade com que um aluno aprende pode ser atribuída à motivação, e sua falta é um fator que leva os estudantes à lentidão ou, em casos extremos, à ausência de aprendizagem".

Por ser necessário um planejamento de aulas, sejam elas presenciais ou não, o professor precisa estar sempre familiarizado com o conteúdo e ferramentas a serem utilizados. Com esse objetivo, no item 3, perguntou-se aos professores o nível de dificuldade encontradas por eles para planejar suas aulas remotas e ao analisar as respostas, verificou-se que dois professores acharam nível neutro, e um nível fácil. Ou seja, de acordo com as respostas dos professores pesquisados, pode-se ressaltar que estes não sentiram dificuldade nessa mudança de ensino.

Como o presente trabalho trata também a questão da aprendizagem dos estudantes durante o ensino remoto emergencial, na questão 4, perguntamos como os professores avaliam o nível de aprendizagem dos estudantes durante o ano letivo 2020. Dos investigados, dois professores responderam que é aceitável e um disse que foi ruim. Diversos fatores podem ser adversos à aprendizagem, principalmente durante o ensino remoto e dentre eles podemos destacar que mesmo os estudantes possuindo acesso "as condições em que vivem e são submetidas se mostram, muitas vezes, desfavoráveis à aprendizagem" (COSTA e NASCIMENTO, 2020 p.3).

Sabemos que "o professor sempre busca formas para motivar os alunos, demonstrando a importância da matemática para o seu futuro, independente da carreira profissional que o mesmo deseje (MOURA, 2019, p.3)" e isso nos fez indagar no item 5 do questionário a opinião dos professores sobre o grau de motivação dos estudantes durante as aulas on-line e obtivemos que dois acreditam que é regular e um ruim. "O interesse do aluno é um aspecto desafiador para o ensino remoto, pois significa tornar a ambiência da apresentação das aulas tão ou mais atrativas do que aquilo que aluno encontrar disponível na rede de comunicação aberta" (GARCIA et al 2020, p. 13).

\subsection{Um "olhar" para o ensino remoto}

Considerando que neste trabalho abordaram-se questões relativas ao ensino remoto, foi importante conhecer a opinião dos estudantes em relação a esse novo ensino. Para verificar a concepção dos alunos em relação ao ensino remoto, utilizou-se um questionário composto por sete (07) questões objetivas, procurando identificar o nível de satisfação dos estudantes do Ensino Médio sobre aulas remotas de Matemática e se as mesmas são suficientes para a aprendizagem; como eles avaliam as aulas de Matemática; se os métodos de ensino dos professores deixaram o conteúdo ministrado mais simples; se estão satisfeitos com o novo método e como se deu a participação desses estudantes durante as aulas do ano letivo de 2020.

Como a pesquisa foi apenas direcionada aos estudantes do Ensino Médio, no questionário, identificamos que dos sessenta e nove (69) participantes, vinte e quatro (24) pertencem à primeira série, trinta e três (33) da segunda série, e doze (12) da terceira série.

Uma das questões procurou identificar o nível de satisfação com o ensino remoto, forneceram-se as seguintes opções: ótimo, bom, regular, ruim e péssimo. Ao verificar essas informações podemos constatar que a maioria dos entrevistados optou pela alternativa bom; em segundo lugar, a opção regular; e apenas 1,4\% opinou que é péssimo. Acredita-se que "a utilização de recursos tecnológicos no processo de ensino [...] torna a aula mais atrativa, proporcionando aos alunos uma forma diferenciada de ensino" (OLIVEIRA, MOURA e SOUZA, 2015, p.76). O gráfico abaixo mostra o resultado detalhado da opinião dos estudantes em relação ao ensino remoto. 


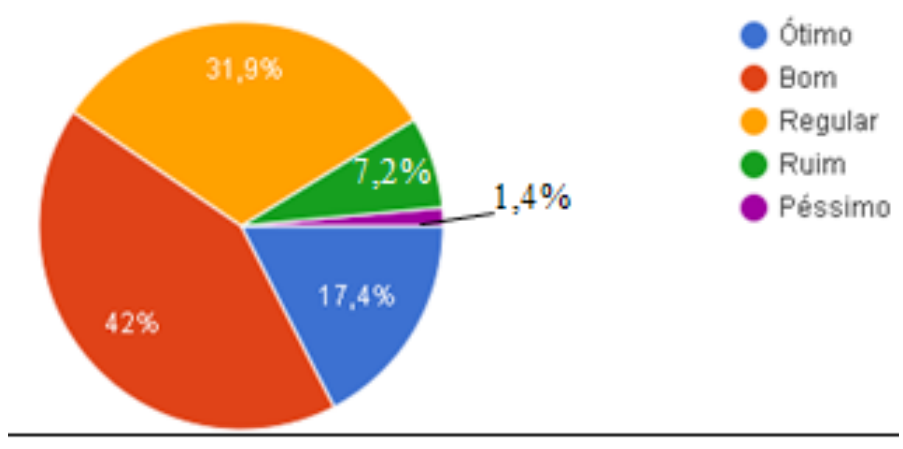

Gráfico 1: Nível de satisfação dos estudantes sobre o ensino remoto.

Fonte: Dados da pesquisa, 2021

No que se referiu se as aulas remotas são suficientes para a aprendizagem, 42\% responderam que não são suficientes, $37,7 \%$ talvez e apenas $20,3 \%$ sim. Muitos fatores podem interferir nessa aprendizagem, até mesmo o contato físico e emocional que os estudantes não possuem durante as aulas remotas. Lottenberg (2021) diz que

[...]as escolas oferecem mais que apenas conteúdos acadêmicos a crianças e adolescentes. Ir à escola não tem a ver apenas com aprender a ler, escrever e a usar a matemática. Lá, os alunos aprendem habilidades sociais e emocionais, fazem exercícios físicos e têm acesso a cuidados com a saúde e a outros serviços de apoio.

Segundo o autor, as aulas presenciais vão além dos conteúdos apresentados pelos professores, lá os estudantes se inter-relacionam, fluindo assim uma aprendizagem mais significativa.

Em relação à avaliação das aulas de Matemática durante as aulas remotas, em uma escola de 1 a 5 , sendo a cinco a mais alta, os estudantes entrevistados assinalaram em maior proporção o nível 4; 19 consideram um nível 3; 15 o nível 5; 4 o nível 2 e apenas 1 o nível. Veja o gráfico abaixo:

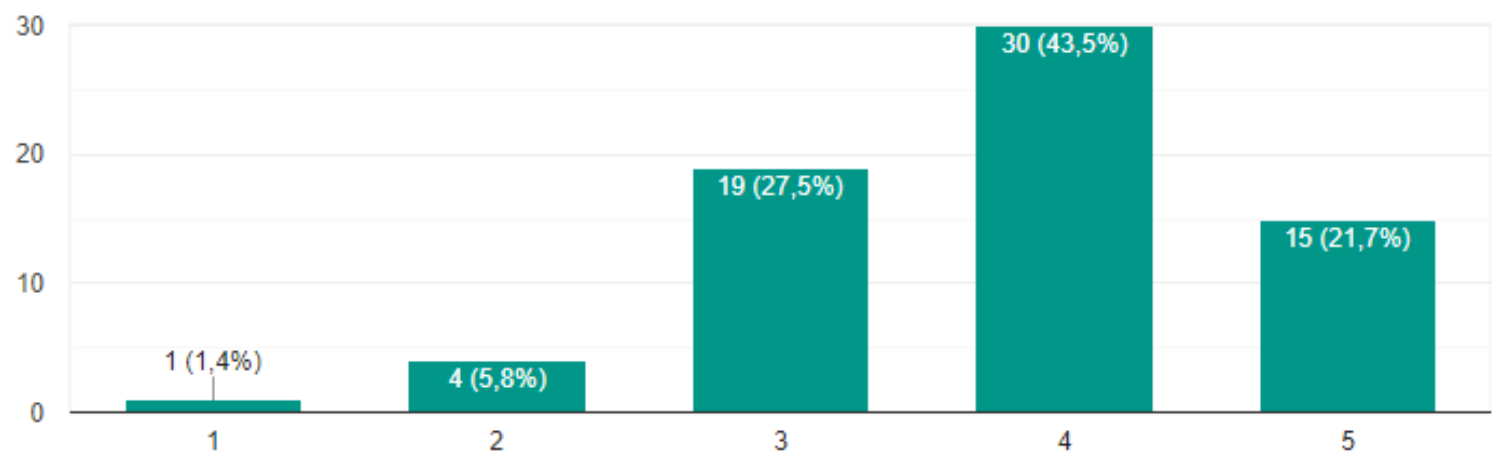

Gráfico 2: Avaliação das Aulas Remotas de Matemática.

Fonte: Dados da pesquisa, 2021

Muitas vezes, a metodologia utilizada pelo professor ajuda no ensino aprendizagem e foi pensando nisto que no item 4 indagou-se os métodos de ensino do professor, ajudaram a entender melhor o conteúdo de Matemática. Nota-se, a partir dos dados coletados, que 33 estudantes disseram que as vezes ajudaram, 32 assinalaram que sim e 4 responderam que não. "O uso adequado e estruturado da tecnologia na Educação, quando aliado ao trabalho docente, pode impulsionar a aprendizagem dos alunos" (CORDEIRO, 2020, p11). 
Com o intuito de verificar se as explicações dos conteúdos de Matemática foram úteis durante as aulas remotas, na questão 5, disponibilizamos 5 opções em que o estudante marcaria apenas uma dessas. 7,2\% consideram que as explicações foram extremamente úteis; 34,8\% muito útil; 29\% útil; 15,9\% pouco útil. Apesar dos desafios, dentre eles podemos destacar que "as ferramentas remotas precisam ter parâmetros de qualidade, para que tenham maior eficácia, e que as desigualdades de acesso às tecnologias, são enormes, haja vista que nem todas as crianças têm computador ou tablet conectados à internet" (CORDEIRO,2020, p.3), não foram empecilhos para que as aulas de Matemática fossem úteis na aprendizagem dos estudantes.

Estudar, seja em qualquer método, há sempre dúvidas em relação aos conteúdos, principalmente a Matemática, disciplina tão temida por uma grande parte dos estudantes. E diante desse novo método de ensino, indagamos aos entrevistados o que eles consultam em caso de dúvida após as aulas remotas, se fazem pesquisa on-line, consultam o professor, assistem a tutorial do YouTube, recorrem aos livros, entre outros. Constatamos que a maioria desses recorrem ao YouTube para assistirem a tutoriais. Observem o gráfico abaixo.

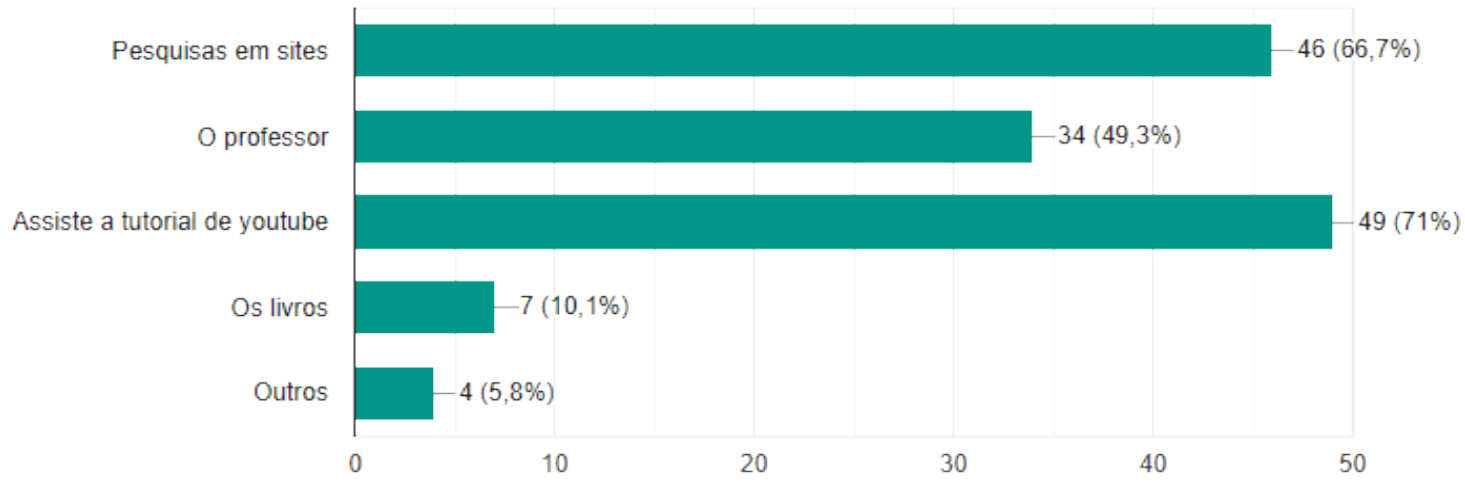

Gráfico 3: Locais onde consultam em caso de dúvidas após aulas remotas.

Fonte: Dados da pesquisa, 2021

Com o novo modelo de ensino, este sendo "a melhor saída para minimizar o atraso no retorno às aulas presenciais" (CORDEIRO, 2020, p.3), houve-se a necessidade de uso de tecnologias, as quais deram suporte para que as aulas remotas acontecessem. E, para isso, utilizaram-se vários aplicativos, dentre eles, o Meet, WhatsAppe o Google Classroom.

Por algum motivo, nem todos os estudantes conseguiram acompanhar essas aulas remotas através dessas ferramentas, seja por não possuir a instrumento tecnológico ou até mesmo não possuir acesso à internet. Para suprir essa carência, as instituições utilizaram portfólios, onde o estudante iria na escola pegar atividades impressas para realizá-las. Assim sendo, buscando compreender como os entrevistados participaram dessas aulas remotas, no último item do questionário, perguntou-se como esses participaram das mesmas, e tiveram cinco opções para assinalarem aquelas em que se identificaram.

Contudo para realização das atividades, 66,7\% fizeram uso do aplicativo WhatsApp; 53,6\% usaram o Classroom; 4,3\% utilizaram o portfólio disponível na escola; $52,2 \%$ assistindo às aulas do professor pelo Meet e 2,9\% não participaram das aulas remotas. Como mostra o gráfico abaixo. 


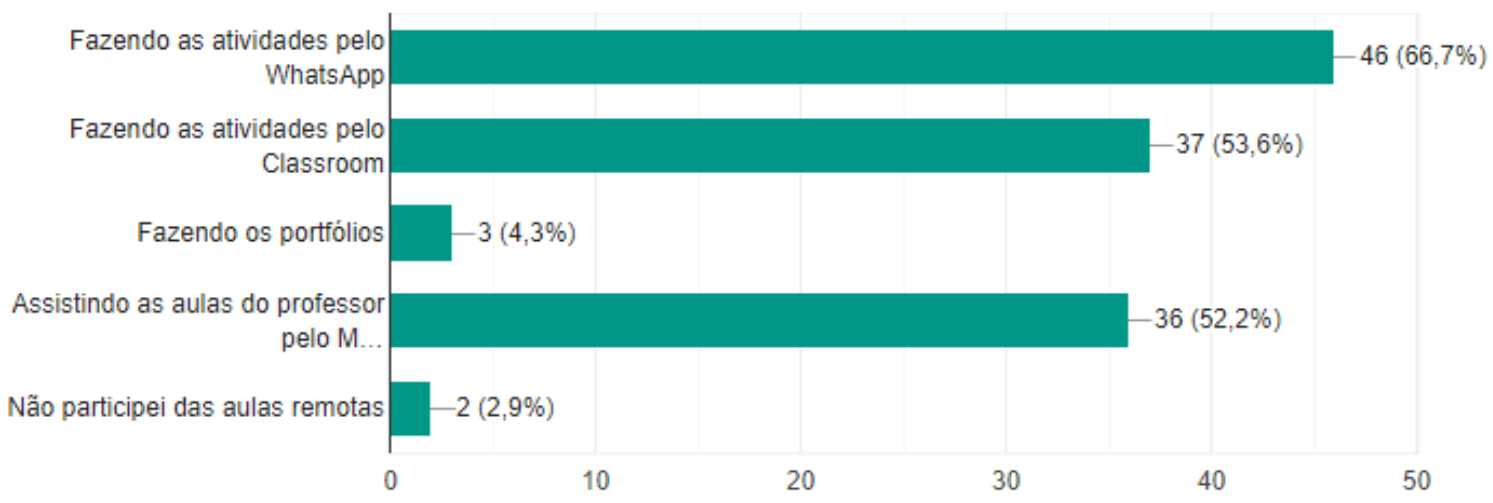

Gráfico 4: Participação das aulas remotas.

Fonte: Dados da pesquisa, 2021

Observa-se que a maioria dos estudantes utilizam mais o aplicativo WhatsApp para participarem das aulas remotas e consequentemente realizarem as atividades postadas pelos professores.

\section{Considerações finais}

Por meio de um estudo empírico, o presente trabalho procurou proporcionar a percepção dos professores de Matemática e estudantes do Ensino Médio do município investigado, em relação ao ensino remoto durante a situação caótica e inesperada que estamos vivenciando, a pandemia da COVID-19. O estudo pareceu propício, tendo em vista a necessidade de uma melhoria no ensino-aprendizagem, que passa necessariamente pela compreensão dos problemas envolvidos.

Com o estudo, constatou-se que durante as aulas de Matemática, muitas vezes, a metodologia utilizada pelo professor ajudou aos estudantes a compreenderem melhor o conteúdo ministrado, sendo que, ao surgirem dúvidas após as aulas, estes procuravam sanar suas indagações através de tutoriais de YouTube e utilizavam outros meios como sites, livros e até mesmo o professor. Apenas com o ensino remoto a aprendizagem torna-se mais complexa, em linhas gerais, este ensino no momento que estamos vivenciando, é apropriado e necessário. Sabemos que ele é um desafio para o ensino e aprendizagem, pois surgiu de maneira inesperada para todos os envolvidos e, embora muitos estudos passassem a abordar esse tema, ainda estamos lhe dando com algo novo, que carece ser revisto e moldado para se tornar acessível a todos.

Quanto à aprendizagem dos estudantes os professores articularam que foi razoável e estes participaram das aulas através de plataformas e aplicativos disponíveis, tais como o WhatsApp e o Classroom. Ao fazer uso das ferramentas tecnológicas para ministrarem suas aulas remotas, estes não sentiram dificuldade para prepará-las e colocá-las em prática, pois já estavam familiarizados com o uso desses aparelhos. Mesmo com todo esforço por parte desses docentes, fazendo uso de tecnologias e um aparato de aplicativos e plataformas para lecionar, não foi o suficiente para que os alunos se sentissem mais motivados a aprender Matemática de forma on-line, entende-se que, por ser uma disciplina que exige uma atenção maior para aprender, justifica-se essa motivação.

Essa pesquisa nos ajudou a ampliar nossos conhecimentos a respeito do uso de tecnologias; do ensino remoto emergencial, o ensino-aprendizagem em tempos de pandemia; bem como a formação continuada, permitindo aos professores uma continuação para expandir os conhecimentos exclusivos de sua profissão. Esperamos que o recorte do problema tratado neste estudo possa servir de estímulo à compreensão de nuances e perspectivas no ensino de Matemática de forma remota. 


\section{Referências}

BEHAR, P. A. O Ensino Remoto Emergencial e a Educação a Distância. 2020. Disponível em https://www. ufrgs.br/coronavirus/base/artigo-o-ensino-remoto-emergencial-e-a-educacao-a-distancia/. Aceso em 24 de julho de 2021.

BRASIL. Lei de Diretrizes e Bases da Educação Nacional, LDB. 9394/1996. BRASIL.

CHIMENTÃO, L. K. O significado da Formação Continuada Docente. $4^{\circ}$ CONPEF. Congresso Norte Paranaense de Educação Física Escolar. - Londrina, Paraná, 2009.

CORDEIRO, K. M. de A. O impacto da pandemia na educação: a utilização da tecnologia como ferramenta de ensino, 2020.

COSTA, A. E. R.; NASCIMENTO, A. W. R. do. Os desafios do ensino remoto em tempos de pandemia no Brasil. Maceió - AL. 2020

D'AMBROSIO, U. Educação Matemática. 2 ed. Papirus: Campinas, 1996.

FRIZON, V. et al. A formação de professores e as tecnologias digitais. Formação de professores, complexidade e trabalho docente - EDUCERE - XII congresso nacional de educação - PUC PR, 2015.

GARCIA, T. C. M. et al. Ensino remoto emergencial: orientações básicas para elaboração do plano de aula. Natal: SEDIS/UFRN, 2020.

LOTTENBERG, C. Volta às aulas presenciais deve ser o objetivo. Veja. 2021. Disponível em

https://veja.abril.com.br/blog/coluna-claudio-lottenberg/volta-as-aulas-presenciais-deve-ser-o-objetivo/. Acesso em: 16 de março de 2021.

MINISTÉRIO DA EDUCAÇÃO. Portaria N³34, de 17 de março de 2020. Disponível em: https://www.in.gov.br/ en/web/dou/-/portaria-n-343-de-17-de-marco-de-2020-248564376. Acesso em: 20 de fereveiro de 2021.

MORAIS, I. R. D. et al. Ensino Remoto Emergencial. Orientações básicas para elaboração do plano de aula. Natal: SEDIS/UFRN, 2020.

MORAN, J. M. Desafios na comunicação pessoal: gerenciamento integrado da comunicação pessoal, social e tecnológica. 3. ed. São Paulo: Paulinas, 2007b. p. 162-166.

MOREIRA, M. E. S. et al. Metodologias e tecnologias para educação em tempos de pandemia COVID-19. Brazilian Journal of health Review, 2020. Disponível em: https://www.brazilianjournals.com/ index.php/BJHR/article/view/11584. Acesso em: 03 fev. 2021.

MOTIN, M. F. et al. O ensino remoto de disciplinas do eixo da matemática em tempos de pandemia, 2020.

MOURA, I. R. de; AMARAL, V. F. F. Fatores que interferem na motivação para o aprendizado da matemática. Fortaleza - CE. 2019.

OLIVEIRA, C. de; MOURA, S. P. Tic's na educação: a utilização das tecnologias da informação e comunicação na aprendizagem do aluno, 2015.

PALÚ, J.; SCHÜTZ, J. A.; MAYER, L. Desafios da educação em tempos de pandemia. Cruz Alta: Ilustração, 2020.

PRODANOV, C. C. Metodologia do trabalho científico: métodos e técnicas dapesquisa e do trabalho acadêmico. 2. ed. novo Hamburgo, RS: Feevale, 2013.

SANTOS, I. G. D. dos; SOUZA, J. R. Educação matemática e mídias tecnológicas: uma possibilidade para a ação educativa? Estudo da porcentagem na 6a série. 2010. 
SANTOS, R. P. dos; JÚNIOR, J. M. M. do N.; DIAS, M. A. de A. As dificuldades e desafios que os professores enfrentam com as aulas remotas emergencial em meio a pandemia atual. Canedu - VII congresso nacional em educação. Maceió - AL. 2020.

SILVA, S. L. et al. Ensino remoto emergencial. -- Ponta Grossa, PR : Ed. dos Autores, 2020.

SILVA, A. Formação Inicial de Professores de Matemática - Vivências Propiciadas Pelo Projeto PIBID. IV Jornada Nacional de Educação Matemática - XVII Jornada Regional de Educação Matemática — Universidade de Passo Fundo, 2012.

VERCELLI, L. de C. A. Aulas remotas em tempos de Covid-19: a percepção dediscentes de um programa de mestrado profissional em educação. Revista @mbienteeducação. São Paulo: Universidade Cidade de São Paulo, v. 13, n. 2, Mai/Ago 2020. 